\title{
Stimulation of nerve endings via medical device
}

\author{
Antonin Svoboda ${ }^{1, *}$, Josef Soukup ${ }^{1}$ \\ ${ }^{1}$ Department of Machine and Mechanics, Faculty of Mechanical Engineering, University J. E. \\ Purkyne, 40001 Usti nad Labem, Czech Republic
}

\begin{abstract}
This solution describes solution of vibromechanism for stimulation nerve paths and nerve endings injured patients. Medical doctors stimulate nerve paths and nerve endings patients after injury of spine or after another injury where was broken nerve endings. These methods are in primary designed for tetraplegic and paraplegic patients specially for men. For this request was developed device and mechanism for vibrostimulation of nerve paths and nerve endings. In develop of construction has been paying attention to safety of mechanism. Next were taken into account the construction of other devices, especially their shortcomings in the operation on the accumulator. For mains powered vibrators 230 (110) Volt were assessed for safety and noise vibrating mechanism. The sum of all failures was proposed structure described below. The success rate of this vibration method is reported mostly between $60-80 \%$.
\end{abstract}

Keywords: vibration, excenter, amplitude, frequency, DC engine

\section{Introduction}

According to available information, and clinical test have mechanisms to induce ejaculation reflex for the collection of genetic material (sperm) in affected males for several years. These methods proved to be reliable with relatively high efficiency [1]. As the most effective method of obtaining genetic material in men can be called surgical sperm collection. This method is performed under general anesthesia, which limits patient. Performance is preceded by internal examination, ECG, blood biochemistry and other examinations according to the patient's condition. Behind this method it is then electrostimulation, which again is performed under general anesthesia by electrical stimulation of the prostate. This method, however, requires a great practical experience of the doctor, as it can cause a burn or burns intestine of the patient. At least stressful method for the patient is vibrostimulation. The doctor or also informed patient stimulates via vibration nerve endings in the penis prescribed amplitude and frequency [2]. After injury of spine are medical doctors ready to help tetraplegic and paraplegic patients return them back normal or near normal life. Most man patients after injury of spine are no able to have got children and family. This status is for most men traumatic and stressful [2]. At least stressful method for the patient is vibro-stimulating.

The doctor or also informed patient vibration stimulates nerve endings in the penis specified amplitude and frequency. To induce ejaculation is after approximately eleven

* Corresponding author: antonin.svoboda.most@seznam.cz

Reviewers: Alžbeta Sapietová, Ján Vavro Jr. 
minutes of stimulation, but it is necessary to observe the procedure three series of stimulation after three minutes and a minute break between every three minutes. Another way to evokes reflection in paraplegics and another way in tetraplegic. Paraplegic person is paralyzed legs, and then the person tetraplegic paralyzed on all four limbs. This method describes ways to return back to life without minimum patient's stresses. One of no stress method is vibro-stimulating of nerve paths [1]. Our developed mechanism is generating vibrations - amplitude and frequencies between effective ranges. After consultations injury doctor specialists, we can presuppose amplitude of the range between $1-3 \mathrm{~mm}$ and frequencies between $80-100 \mathrm{~Hz}$.

For optimal frequency and amplitude, we can take information from doctor's injury and convalescence specialists. Finally, we can make a proposal optimal frequency and amplitude [1]. For the best solution we can mark range between $80-120 \mathrm{~Hz}$ and $1-4 \mathrm{~mm}$ [3]. To achieve the desired frequency, range between $80-120 \mathrm{~Hz}$, it is necessary to convert frequency to RPM of DC engine speed (1).

$$
f=\frac{n}{T}[\mathrm{~Hz}] \Rightarrow n=f \cdot T \Rightarrow n=f \cdot 60 .
$$

Where is $f$ - frequency, $n$ - DC engine speed in RPM (rotation per minute), $T$ - time

Unbalance in rotating machines is a common source of vibration excitation [4]. We consider here a spring-mass system constrained to move in the vertical or horizontal directions and excited by a rotating machine that is unbalanced, as shown in Fig. 1, 2. The unbalance is represented by an eccentric mass $\mathrm{m}$ with eccentricity e that is rotating with angular velocity $\omega[5]$.

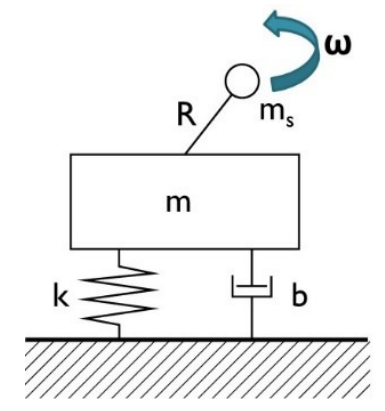

Fig. 1. Forced damped vibration system with one degree of freedom

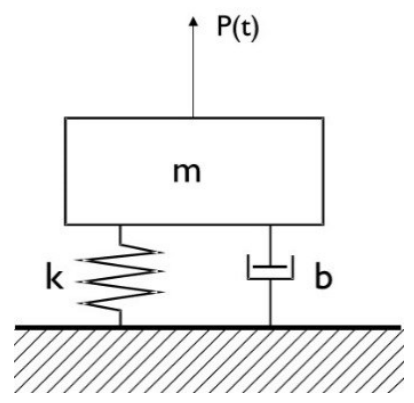

Fig. 2. Forced damped vibration system with one degree of freedom

Where is $m_{s}$ - weight of particles, $m$ - weight, $R$ - eccentricity, $\omega$ - angular velocity, $b-$ coefficient of shock absorber, $k$-stiffness of the spring 
Equation of motion

$$
m \ddot{x}+b \dot{x}+k x=P(t)
$$

where is $x$ - the displacement from the static equilibrium of position, $P(t)-$ the excitation of power

Angular speed

$$
\omega^{2}=\frac{k}{m}
$$

Harmonic oscillation is characterized by harmonic waveforms

$$
\begin{gathered}
y=y_{0} \sin (2 \pi f)=y_{0} \sin \omega t \\
a=\frac{d v}{d t}=-\omega^{2} y_{0} \sin \omega t=a_{0} \sin \omega t \\
v=\frac{d y}{d t}=y_{0} \omega \cos \omega
\end{gathered}
$$

where is $\omega$ - angular velocity, $y_{0}$ - amplitude of displacement, $a_{0}$ - amplitude of acceleration, $t$ - time.

\section{Methods}

Vibration that takes place under the excitation of external forces is called forced vibration. When the excitation is oscillatory, the system is forced to vibrate at the excitation frequency. If the frequency of excitation coincides with one of the natural frequencies of the system, a condition of resonance is encountered, and dangerously large oscillations may result. The failure of major structures such as bridges, buildings, or airplane wings is an awesome possibility under resonance. Thus, the calculation of the natural frequencies of major importance in the study of vibrations [5]. The mechanism was designed in several variants. Theoretical solution can be effective via analytics method, method of final points and experimental measurement. For the best solution can be mark experimental measurement. For making these tests of experimental measurement was designed vibrogenerator with DC engine in several variants. In all variants was used the same electric engine SPEED 400 with maximum 12000 RPM and powered between 6-12 Vols. For medical device - vibrogenerator is effective RPM between 4800 - $7200 @ 3,32$ - 4,81 Volts. Crank mechanism Fig. 3. is very difficult and expensive for production in this very small sizes. Is necessary to take into consideration more difficult assembly of mechanism device [3]. Advantages: Precisely adjustable amplitude shift crankshaft, separation of amplitude from frequency - with increasing of the engine speed (frequency) is the amplitude constant. Disadvantages: Miniature parts of the crank mechanism - higher demands on production and assembly [6]. 


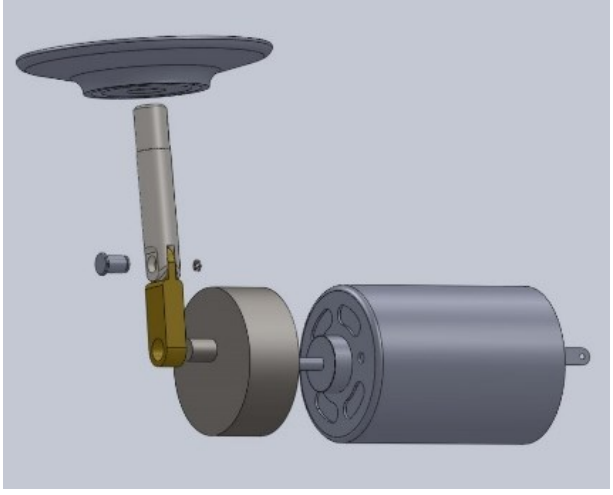

Fig. 3. Crank mechanism

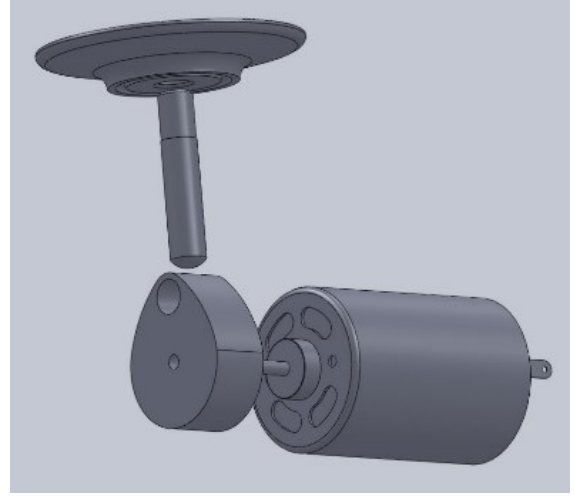

Fig. 4. Construction with the cam

A cam mechanism (Fig. 4) provides the distinct advantage the simplicity of design [7], the lower cost of the assembly apparatus, than the variants with the crank mechanism [8]. Advantages: Simplicity of design - lower assembly costs and assembly of device mechanism. Disadvantages: Complicated of cam production, noise of the device. When we would like to use a cam mechanism, it is necessary to take into account unbalance cam which causes the vibration of the whole device. In this case, unbalance works in favour of the final oscillation amplitudes, but to the detriment of engine bearings and the entire device. At the prescribed speed in the range $4800-7200$ RPM occurs due to imbalance even more options, so-called own auto oscillations [8].

Eccentric is probably the simplest design of solution, bringing low manufacturing costs. Experimental measurements with eccentric showed higher noise of the device. Advantages: Simplicity of design. Disadvantages: Higher load of engine's bearings, noise of the device. Unbalance Fig. 5. and Fig. 6. is the simplest solution, however, the fundamental problem depending engine speed (frequency) vs. amplitude. Advantages: Simplicity of design. Disadvantages: Higher load of engine's bearings, frequency dependence of the amplitude.

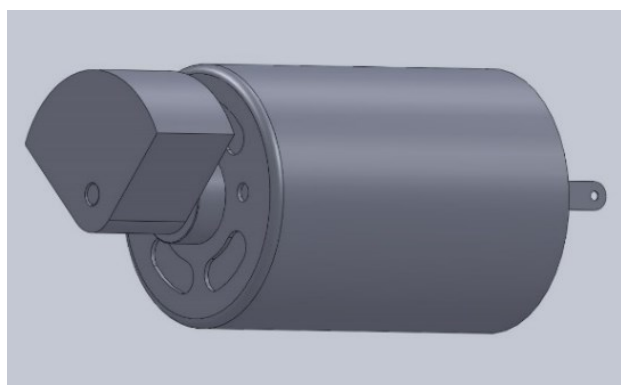

Fig. 5. Construction with the unbalance

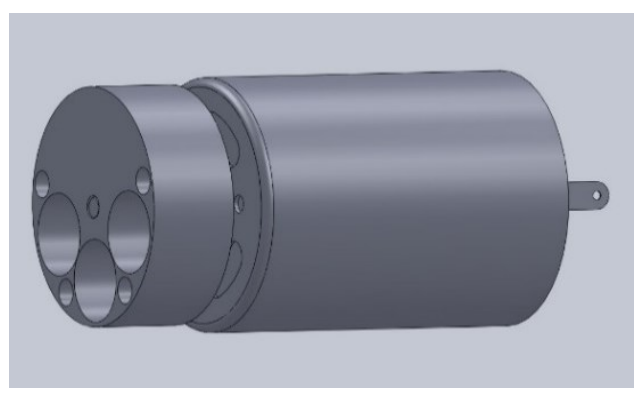

Fig. 6. Constructions with drilled unbalance holes are the most simpler from a manufacturing point of view

\section{Results}

With experimental measurements we found optimal values of amplitude and frequency. In the future, these results will be used for the final design of the device for generating vibrations. Unbalance method was verified in the laboratory. DC engine was powered by a stabilized source and were measured engine's RPM, the electric current (A) and frequency 
(Hz). RPM of DC engine was taken via laser method of scan. The final frequency of unbalance mechanism of medical device, was taken by three axes accelerometer.

At Fig. 7, 8, 9 are shown graphical acceleration $\left[\mathrm{m} / \mathrm{s}^{2}\right]$ (axes $\mathrm{Y}$ ) and frequency $[\mathrm{Hz}]$ (axes X) what were recount to amplitude [mm] via La Grange method. Frequency of DC engine was controlled via laser RPM equation (1).

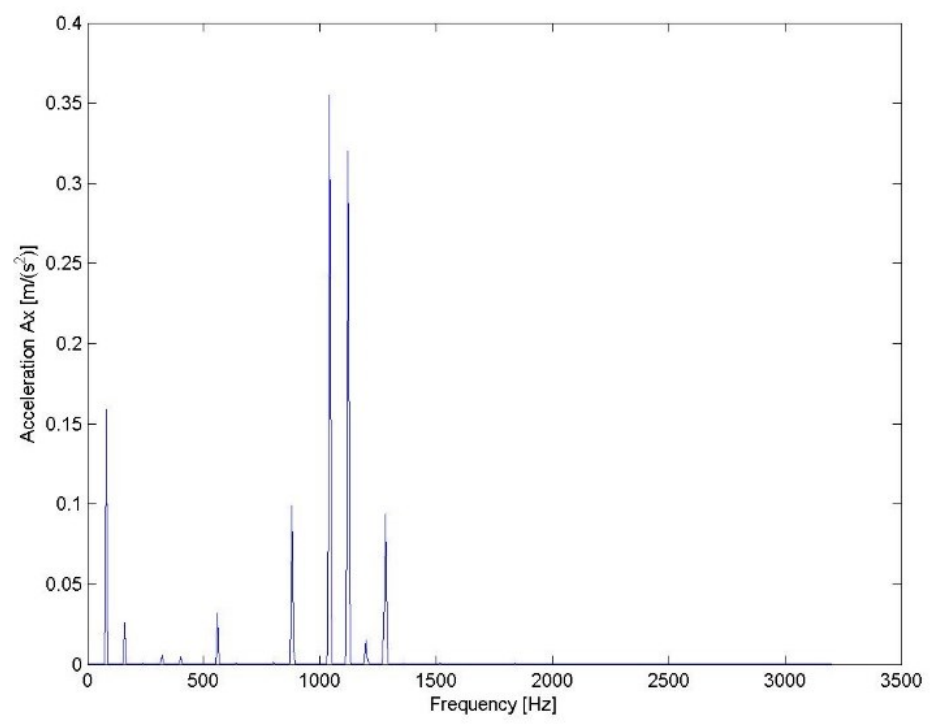

Fig. 7. Acceleration in the $x$ direction - measurements at speed 4800 RPM

In Fig. 7 was achieve the maximum of acceleration value $0.3549 \mathrm{~m} / \mathrm{s}^{2}$ in frequency 1040 $\mathrm{Hz}$ via $4800 \mathrm{RPM}$ of DC engine. These values were recalculated to amplitude and later theoretically confirmed via Lagrange numerical mathematics method.

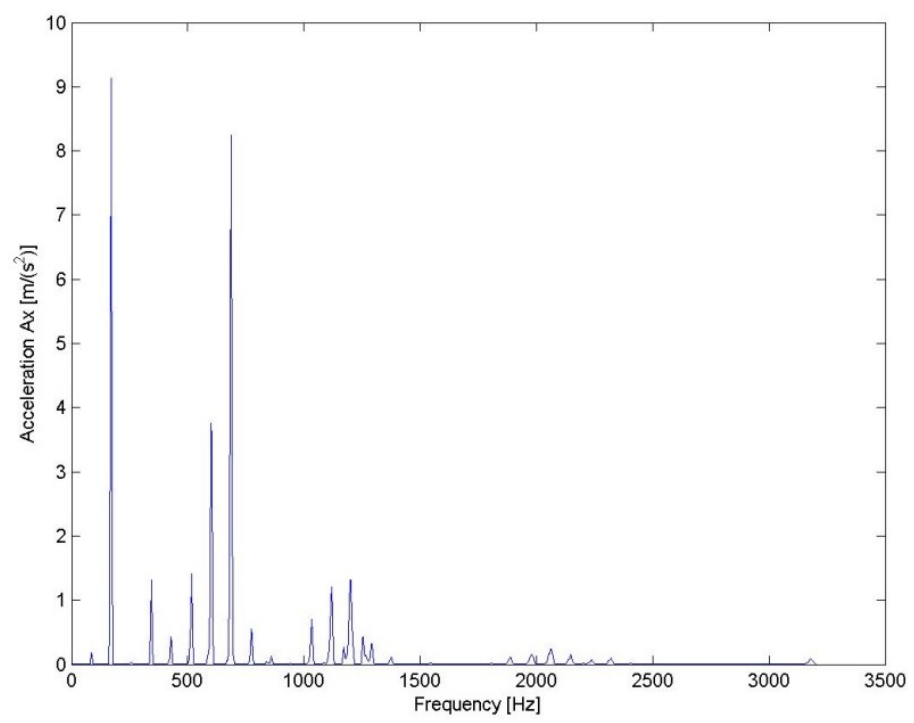

Fig. 8. Acceleration in the y direction - measurements at speed 5160 RPM 
In Fig. 8 was achieve the maximum of acceleration value $9.1390 \mathrm{~m} / \mathrm{s}^{2}$ in frequency 172 $\mathrm{Hz}$ via $5160 \mathrm{RPM}$ of DC engine. These values were recalculated to amplitude and later theoretically confirmed via Lagrange numerical mathematics method.

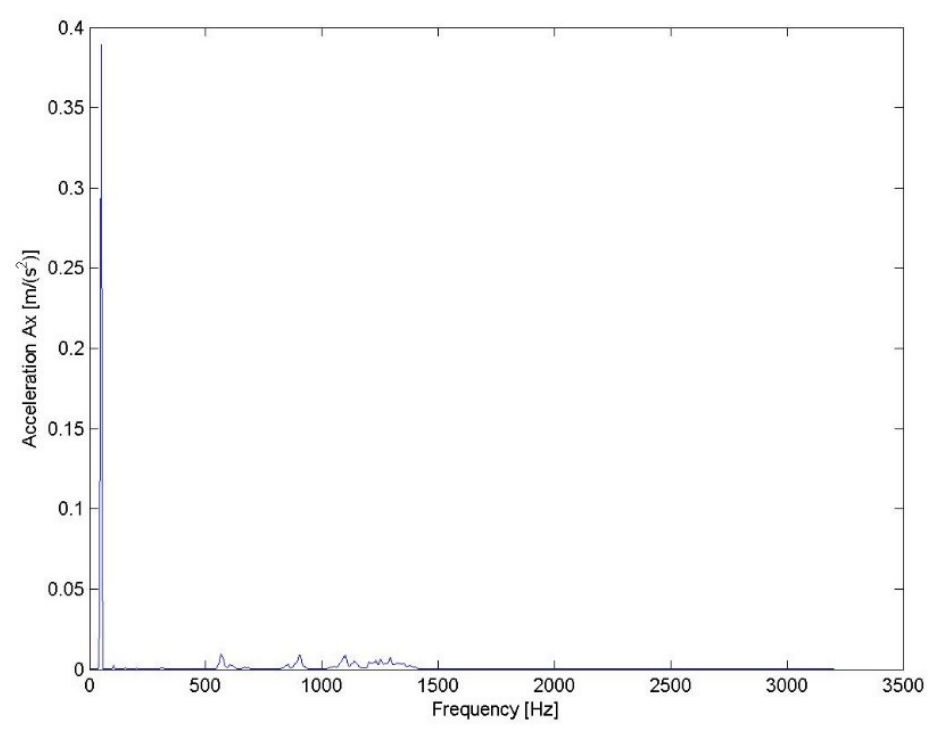

Fig. 9. Acceleration in the $\mathrm{z}$ direction - measurements at speed $3060 \mathrm{RPM}$

In Fig. 9 was achieving the maximum of acceleration value $0.3892 \mathrm{~m} / \mathrm{s}^{2}$ in frequency 52 $\mathrm{Hz}$ via $3060 \mathrm{RPM}$ of DC engine. These values were recalculated to amplitude and later theoretically confirmed via Lagrange numerical mathematics method.

\section{Conclusions}

For measurement of vibrations was designed special stand. In all cases of tests were used the same engine SPEED 400 powered by stabilized source. RPM was taken via laser sensor and vibration was measured via accelerometer. All measurement results were recalculating from acceleration to amplitude and was used numerical method Lagrange for verifying this values. Next were processed via software MATLAB and converted to MS-EXCEL. In these methods described above was compared vibration exciter suitable mechanism design. Was selected the most appropriate method of construction equipment. This method was experimentally verified in laboratory. It will also be developed by the cheapest method of production and assembly device for vibration excitation and stimulation of nerve endings and paths. The result of this work will be quality and cheap device for stimulating man patients.

J. E. Purkyne University in Usti nad Labem, Faculty of Production Technology and Management for support of this project from SGS grant.

\section{References}

1. T. Šrámková, Poruchy sexuality u somatických nemocných a jejich léčba. Grada Publishing, 27-32 (2013)

2. K. Juliš, R. Brebta, a kol., Mechanika I. - Statika a kinematika. (SNTL Praha, 1986) 
3. Z. Dejl, Konstrukce stroju a zař́zeni I. Spoje. (Montanex, Ostrava, 2000)

4. H. Benaroya, Mechanical vibration. (Marcel Dekker, N.Y., 2004)

5. J. R. Ellis, Road Vehicle Dynamics. (Ahron, USA, 1989)

6. R. Brebta, L. Půst, F. Turek, Mechanické kmitání. (Sobotáles, Praha, 1994)

7. A. Svoboda, Mechanický př́stroj pro stimulaci nervových drah. Diplomová práce, Fakulta výrobních technologií a managementu UJEP v Ústí nad Labem, Ústí n. L., (2015)

8. V. Vejrosta, Konstrukce zdravotnických př́strojů. (Česká společnost pro zdravotnickou techniku, June, 1995) 